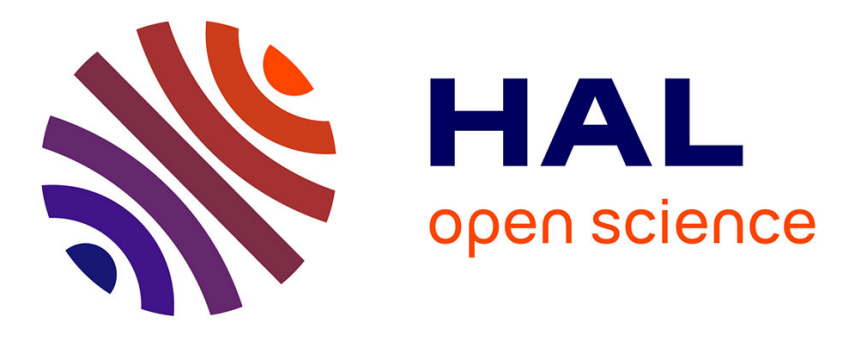

\title{
Poincaré: intuitionism, intuition, and convention
}

Gerhard Heinzmann, Philippe Nabonnand

\section{To cite this version:}

Gerhard Heinzmann, Philippe Nabonnand. Poincaré: intuitionism, intuition, and convention. Mark van Atten, Pascal Boldini, Michel Bourdeau, Gerhard Heinzmann. One Hundred Years of Intuitionism (1907-2007), Birkhaüser, pp.163 - 177, 2008, Publications des Archives Henri-Poincaré, 978-3-76438652-8. 10.1007/978-3-7643-8653-5_11. hal-01083141

\section{HAL Id: hal-01083141 https://hal.science/hal-01083141}

Submitted on 15 Nov 2014

HAL is a multi-disciplinary open access archive for the deposit and dissemination of scientific research documents, whether they are published or not. The documents may come from teaching and research institutions in France or abroad, or from public or private research centers.
L'archive ouverte pluridisciplinaire HAL, est destinée au dépôt et à la diffusion de documents scientifiques de niveau recherche, publiés ou non, émanant des établissements d'enseignement et de recherche français ou étrangers, des laboratoires publics ou privés. 


\title{
Poincaré: Intuitionism, Intuition and Convention
}

\author{
Gerhard Heinzmann/Philippe Nabonnand ${ }^{1}$
}

I. Arend Heyting in the introduction of his famous volume on Mathematische Grundlagenforschung, Intutionismus, Beweistheorie, speaks of Poincaré's influence on "contemporary intuitionists" i.e., mathematicians who agree with the opinion that

(1) Mathematics has not only a formal but also a contentual signification.

(2) Mathematical objects are immediately grasped by the thinking mind; hence the mathematical knowledge is independent of experience. [Heyting 1934, 3] ${ }^{2}$

In addition, according to Heyting, the second characteristic is essentially connected with ontology and admits two different interpretations:

a) Mathematical entities don't exist independently of our thinking (anti-realism)

b) Mathematical entities exist independently of us but are only knowable through construction.

Heyting attributed the first interpretation to Brouwer and called the second position semiintuitionistic. The term was motivated by systematic considerations. One of these was the fact that the grasping of the entity might not be immediate but mediated by linguistic construction. Heyting saw the semi-intuitionistic rejection of a construction-transcendent notion of existence as approximating Kronecker's view, and he saw it as even in a wider sense the view of the "French realists or empiricists," among which were Borel, Lebesgue, Baire, Kaufmann, Skolem and Richard. I think he is right to have omitted Poincaré from this list. Clearly, for Poincaré, the question of mathematical entities existing independent of our mind is a question of old metaphysics about which he had nothing to say $[\mathrm{SH}, \mathrm{XXIV}]^{3}$.

Since Kant, mathematical intuition has been connected with construction. But constructivism could neither be identified with intuitionism (anti-realism) nor with realism. What it is that is supposed to be constructible, objects or proofs, remains a subject of debate and is linked neither with thesis (a) nor with thesis (b). Brouwer recognized mathematics as an autonomic interior constructional mental activity [Brouwer 1955, 551; my emphasis]. Moreover, although constructivism was a key word in Kronecker's attack against Cantor's platonism and, in a wider sense, against traditional (axiomatic) mathematics, the question of construction has a definite sense even for a Platonist. This is illustrated by Gödel's attitude towards constructible sets. Generally speaking, Gödel believed that mathematical objects can be perceived through a special cognitive ability, i.e., "intuition", in something like the same way that empirical objects are grasped through sensory perception. As Hintikka put it, the intuitionist is more interested in what we can know whereas the constructivist is more interested in what we can $d o$ [Hintikka 1996, p. 237]. In any case, constructivism and

\footnotetext{
${ }^{1}$ Laboratoire d'Histoire des Sciences et de Philosophie - Archives Poincaré (UMR 7117). Université de Lorraine \& CNRS.

${ }^{2}$, ,1. Mathematik hat nicht bloß formale, sondern auch inhaltliche Bedeutung. 2. Die mathematischen Gegenstände werden von dem denkenden Geist unmittelbar erfaßt ; die mathematische Erkenntnis ist daher von der Erfahrung unabhängig."

${ }^{3}$ According to Poincaré modern metaphysics negates all metaphysics and constitutes for this reason nevertheless a metaphysical standpoint (see letter to Camille Flammarion, 1904, Bulletin de la Société astronomique de France 18, 216-21719004)
} 
intuitionism are both neutral with respect to realism and anti-realism. Anti-realism doesn't imply intuitionism, and realism doesn't imply an anti-intuitionistic constructivism. In addition, since historical positions don't necessarily coincide with these normative views, and their opposition is rather contrived [see [Mooij 1966, 136]].

It was Brouwer himself who pressed the difference between (a type of) constructivism and intuitionism by comparing Poincaré's position with his own standpoint. He saw Poincaré as guilty of a "confusion between the act of constructing mathematics and the language of mathematics." [Brouwer 1907, 176]. Although, according to Brouwer, the constructional mental activity of intuitionism may have a useful linguistic expression and can be applied to an exterior world, it has "neither in its origin nor in the essence of its method [... ] anything to do with language or an exterior world" [Brouwer 1955, 551].

Poincaré was far from taking the nonlinguistic and intuitive construction as the only basis for mathematics. The role of linguistic conventions and language in mathematics is a point that separates him from Brouwer. For Brouwer, "the mistake of logistics lies in the fact that it creates nothing else other than a linguistic structure, which can never be transformed into mathematics proper" [Brouwer 1907, 176], for Poincaré, mathematics proper beyond linguistic structures is not a knowable domain. The evidence of object-constructions has to be linked with their description (By the way, this "pragmatistic" turn of Poincaré's philosophy is the French origin of analytic philosophy). Nevertheless, Brouwer is quite right when he emphasizes that Poincaré "reestablished on the one hand the essential difference in character between logic and mathematics, and on the other hand the autonomy of logic and of a part of mathematics" [Brouwer 1952, 140]. In fact, according to Poincaré, the program of founding number theory on logic involves a petitio principii because this foundation presupposes already some number theory. It seems that even his theory of predicative definitions was taken to be independent of mathematics [cf. Goldfarb 1988, 64]. Expressed in other words, even though Poincaré may have agreed with Brouwer that "mathematical language by itself can never create new mathematical systems" [Brouwer 1952, 141], mathematical language is nevertheless a necessary tool for mathematical creation (and not, or at least not merely, in a some psychological way). I will discuss this point later.

Hence there are epistemological features that bring some single results of Poincaré's position close to those of Brouwer's; however, Poincaré's thinking cannot be assimilated to Heyting's definition of semi-intuitionism.

Let us return to Heyting's characterization of intuitionists that we began with. Can one say that (1) and (2) were influenced by Poincaré? If so, in what sense(s)?

Concerning the first point, regarding the claim that mathematics has not only a formal but also a contentual signification, one can, following Colin McLarty, contrast three kinds of interpretation: banal, expansive and restrictive [Mc Larty 1997, 97]. The banal interpretation merely says mathematics requires something beyond formal rigor ${ }^{4}$. The expansive interpretation claims that the content of mathematics goes beyond any formalization. The restrictive interpretation rejects some standard mathematics as inaccessible to intuition or a constructive procedure.

\footnotetext{
${ }^{4}$ This is expressed by Pierre Boutroux [1920,170]: "There is some other thing beyond the logical form [of mathematics]".
} 
Brouwer was an expansive and a restrictive intuitionist. The application of his mental construction principle to semantics and ontology lead to his rejecting both the universal validity of the principle of the Excluded Middle (by conceiving a restrictive alternative logic) and the continuum of classical analysis. The question is whether Poincaré was more than a banal "intuitionist". His oft-quoted statement [cf., for example, Largeault 1993, 37 or Resnik 1996, 459] in favor of banal intuitionism is this: "Logic, which alone gives certainty, is the instrument of demonstration; intuition is the instrument of invention" [VS, 23 (37), SM, (130)]. This, however, was intended only as a summary of a discussion about the distinction between sensible intuition and analytic procedures. Some pages later, he underlined that pure intuition gives certainty too and enables us to demonstrate and to invent [VS, 25 (39) $]^{5}$.

One may expect from the literature that, as a philosopher, Poincare was both, too, expansive and restrictive concerning foundational questions. Concerning the restrictive character of Poincaré's philosophical position, Brouwer recalled quite rightly his predicativism and his rejection of the actual infinite that were both consequences of his pragmaticism. Poincaré, he noted, "blames in logistics the petitio principii and in cantorism the hypothesis of the actual infinite" [Brouwer 1907, 176]. Clearly, Poincaré didn't reject classical logic. His view, formulated in modern terms, was that the various formal-logical theories don't express the proof-theoretical structures that constitute our understanding of mathematics [Cf. SM, 149 (159)]. He rejected the invariance of mathematical reasoning with regards to its contents and promoted, so to speak, a "local" conception of mathematical reasoning according to which "a 'gap' is no longer a logical gap but, rather, a gap in mathematical understanding" [Detlefsen 1992, 366, 360] and, as such, a gap that cannot be eliminated through formalization. "Mathematical reasoning is thus no longer to be seen as a primarily logical relationship between propositions, but rather as an epistemic relationship between judgments" [Detlefsen 1993, 270]. In this sense Poincaré has an expansive understanding of the contentual signification of mathematics.

Let's assume that it makes sense to distinguish Poincaré as philosopher from Poincaré as mathematician. Could one also say that even the mathematician Poincaré was more than a banal "intuitionist" in the sense of attributing to mathematics some contentual significance?

In order to discuss this question we need to clarify in what sense the content of mathematics goes "beyond any formalization".

Taking the term "intuitionism" for the view "that mathematics must ultimately be based on the irreducible intuition of counting, of the natural numbers as a potentially infinite sequence", Harold Edwards [1988, 140], thinks to have found a common factor for proponents "including Henri Poincaré, L.E.J. Brouwer, Hermann Weyl and Errett Bishop" [ibid.]. According to this perspective, Poincaré could perhaps be called semi-intuitionist because he was intuitionist only in arithmetic, or perhaps also in set theory concerning the methods of proofs used therein. I examine only the first possibility, arithmetic. What does it mean that we have an irreducible intuition of counting? Here the second point of Heyting's characteristic is important: it requires an irreducible intuition of counting which, at the same time, has to be grasped by our minds in a non mediated way and independently of non mental experience. But unfortunately, Poincaré did not think that the sequence of natural numbers is completely independent of all experience of the outer world:

\footnotetext{
${ }^{5}$ Poincaré, in considering pure intuition as a faculty of the intellect, draws on the Neo-Kantian heritage.
} 
We have the faculty of conceiving that a unit may be added to a collection of units. Thanks to experiment, we have had the occasion of exercising this faculty and are conscious of it. [SH, 24; our emphasis]6

In other words, the schema $\mathrm{R}$ :

$$
\begin{gathered}
\mathrm{N}(\mathrm{I}) \\
\forall \mathrm{x}[\mathrm{N}(\mathrm{x}) \rightarrow \mathrm{N}(\mathrm{xI})],
\end{gathered}
$$

is occasioned by experience without having to be empirical.

Now, as is well known, Poincaré considered the principle of complete induction to be a synthetic a priori principle because it is "imposed upon us with such a force that we could not conceive of the contrary proposition" $[\mathrm{SH}, 48]^{7}$. Why then is it not analytical? Poincaré's concept of an analytical judgment is not the Kantian one but that of Frege and concerns the means of proof: the principle is not analytic because it is "inaccessible by analytical proof" $[\mathrm{SH}, 12]$. One can fix an operation which, if applied to a chosen numeral $n$, leads to a proof of $N(n)$. But how are we to be sure that all numbers are covered by the range of $R$ ? And how can we secure the validity of arithmetic without applying induction? This would clearly be a vicious circle. Nor is there a uniform proof-skeleton, because the length of proof that is the number of applications of modi ponentes depends on $n$. It follows, then, that a single proof is not to be read as apprehension of a schema-instance:

A construction only becomes interesting when it can be placed side by side with other analogous constructions for forming species of the same genus. [... ] The analytical process 'by construction' [... ] leaves us at the same level. We can only ascend by mathematical induction. [SH, 16]

According to Poincaré, mathematical induction cannot be identified with an 'analytical' construction process. It is not on the same level because it expresses, so to say, an infinity of modi ponentes, which means that it is synthetic. Technically, we have the fact that the direct clauses of the inductive definition of numerals (that is $R$ ) do not analytically imply the final clause (or equivalently, the principle of induction) ${ }^{8}$.

[The principle of induction] is only the affirmation of the power of the mind which knows it can conceive of the indefinite repetition of the same act, when the act is once possible. The mind has a direct intuition of this power, and experiment can only be for it an occasion of using it, and thereby of becoming conscious of it. [SH, 13, our emphasis]

The awareness of the mind's power of indefinite repetition $(\mathrm{R})$ is also occasioned by experience, $e . g$. of concrete stroke concatenation, and it is the affirmation of this capacity that yields the induction principle. The intuition of the mind's power is a priori because the action-schema is the result of our own creation. A pure intuition can be distinguished from simple evidence by the fact that it refers to what can be done instead of merely to something

\footnotetext{
${ }^{6}$ Poincaré often emphasizes that experiment is powerless to grasp reasoning by recurrence although it is an occasion to remind us of the capacity we have for it: "We may say, for instance, that in any finite collection of different integers there is always one which is smaller than any other. We may readily pass from one enunciation to another [...] Experiment may teach us that the rule is true for the first ten or the first hundred numbers for instance; it will not bring us to the indefinite series of numbers." [ $\mathrm{SH}, 12]$

${ }^{7}$ Poincaré's understanding of Kant on synthetic a priori judgments is debatable; see [Ben-Menahem 2001, 476; especially note 14].

${ }^{8}$ Cf. [Poincare 1906, 303]. The final clause says that the only instances are those provided by the clauses of $\mathrm{R}$ (cf. [Kleene 1980, 21/22]).
} 
that is. The principle of induction is synthetic because it is not generated but only represented by the action schema: the principle postulates a survey of a potentially reiterated strokeconcatenation, or a survey of a potentially reiterated modus ponens.

What is important here is that the principle is thought to be the structural component of empirical constructions: the induction principle is occasioned by experience without having to be empirical and constitutes as such the theoretical part of our knowledge. Experience is the ratio cognoscendi of the principle of induction. So it seems clear why the negation of the principle is not conceivable: the principle of induction is a form of understanding, in the sense that "we can form no conception of an experience which would be best interpreted as a violation of it" (cf. [Folina 1992, 32]). The universal proposition of induction, as used by Poincaré, is neither used qua convention nor qua intuition in the sense of Heyting's criteria. So, Poincaré's influence on this latter, though not very deep, is nonetheless not completely disconnected ${ }^{9}$. In general, experience is for Poincaré by no means a sufficient source of knowledge; it plays, above all, the role of making us aware of the existence of certain structures of the mind to which we have to accommodate our experience, directly as in the case of complete induction or, by the introduction of conventions, as in geometry.

Moreover, Poincaré himself asserted that complete induction is only the simplest of all "other similar principles, offering the same essential characteristics" [SM 149/150 (159/160)]. Such analogous principles are especially the awareness of our capacity to construct a continuum of any dimension, called topological intuition. This concept pre-exists, according to Poincaré, in our mind as a form of reason and the awareness of them is occasioned by experience [cf. DP, 157, 134sq.; SH, 87sq.].

We will see in the next section, that the elaboration of conventions in geometry is analogous to the "genesis" of the induction principle although the a priori status of complete induction clearly contrasts with that of conventions.

II. - How does Poincaré use the term 'convention' in geometry? At a first approach his geometrical conventionalism consists of three theses:

i) Experience does not relate to space, but to empirical bodies. Geometry deals with ideal bodies, and it can therefore be neither proved nor disproved by experience. Since the propositions of geometry cannot be analytical either, these propositions must then be conventions, neither true nor false [SH, 50].

ii) The choice between conventions, and in particular between different geometries, is guided by experience [SH, 50].

iii) Euclidean geometry has nothing to fear from experience, for it is the most advantageous and convenient one [SH, 73].

In order to understand this threefold thesis, we will respect Poincaré's analysis of his own scientific work, [Poincaré 1921, 127] where he underlines that the first step of his reflection concerning the construction of geometrical space ${ }^{10}$ is its psycho-physiological genesis linking

\footnotetext{
${ }^{9}$ Beth's judgment seems quite striking: 'Poincaré's ideas stimulated Brouwer', not more but not less [Beth 1956, 233].

${ }^{10}$ The essential properties of geometric space are: " 1 st, it is continuous; 2 nd, it is infinite; $3 \mathrm{rd}$, it is of three dimensions; 4th, it is homogeneous - that is to say, all its points are identical one with another, 5th, it is isotropic. Compare this now with the framework of our representations and sensations, which I may call representative space" [SH, 52]. In fact, "it is neither homogeneous nor isotropic; we cannot even say that it is three dimensional." [SH, 56]
} 
sensible space to geometric space. ${ }^{11}$ Geometrical space is obtained by choosing the language of groups to serve as the tool of reasoning about representations of muscular sensations. As a result of this genesis, Poincaré finds that certain actions, when accompanied by muscular sensations, define equivalence classes, called displacements, and that each set of displacement classes forms a group in the mathematical sense. Thereby the edge of Poincaré's creative virtue in arithmetic, i.e. repetition, is also necessary in the psycho-physiological genesis of geometry:

Repetition [... ] has given to space its essential characteristics; now, repetition supposes time; this is enough to tell that time is logically anterior to space. [VS, 72]

Surely, there is a 'family resemblance' with Brouwer's time progression but only if one substitutes 'ontologically' for 'logically' [Février 1981, 167].

Now, after having argued the idea that the genesis of space depends on the genesis of a group of transformations in his first papers about that question, Poincaré seems, in 1903 to concede to the idea of the existence of an amorphous continuum as a kind of primary frame for the genesis of geometry and geometrical space. Poincaré, for some reasons of coherence, is compelled to revise parts of his original theory and to renounce his claim that there is no need to presuppose a "3-dimensional Zahlenmannigfaltigkeit" as the matter on which groups of transformations act. He revised his theory in two papers first published in the Revue de métaphysique et de morale and later in La Valeur de la science. In these two papers, Poincaré placed a new emphasis on topology which he presented as qualitative geometry as prior to quantitative geometries.

In his paper about the nature of geometry [Brouwer 1909], after claiming the impossibility of arguing convincingly that Euclidean geometry is a priori, nevertheless conceded the existence of an a priori form of the perception of the world of experience that he called "the intuition of time or intuition of two-in-one" [Brouwer 1909, 116]. He defined this as the mathematical intuition of continuous time, extraneous to the idea of measure as conceived by a singular subject. Because of this claim, it can be argued that Brouwer was already defending a kind of intuitionist point of view in geometry, at least in the weak understanding in the sense of Edwards or Heyting.

For Brouwer, geometry is the science of "properties of spaces of one or several dimensions". Geometers study and classify sets, geometrical transformations and groups of transformations in these spaces. Brouwer attached a particular status to the groups of topology (i.e. the groups of continuous transformations) because of their ubiquity and because "a figure only unfolds its internal properties while for its definition only invariants of the largest possible group are used." [Brouwer 1909, 118].

The question is: Does Poincaré's revision of his claim and his putting Analysis situs at the basis of geometry make him a defender of a point of view analogous to Brouwer's? Such an idea may be reinforced by the strong link between Poincaré's definition of topological dimension and that of Brouwer (inspite of the latter's criticism of the former's argumentation). Our claim is that this analogy is totally superficial and that the geometrical conceptions of Poincare are radically different from those of Brouwer for the same reason as in arithmetic.

\footnotetext{
${ }^{11}$ Poincaré's original conventionalism is not related to the general axiomatic method in Hilbert's sense. Influenced by Sophus Lie's theory of group transformation, he considers geometry to be nothing but the study of certain groups and subgroups.
} 
The geometrical conventionalism of Poincaré is well-known, but the conventional aspects of geometry are not restricted only to the choice of the most "commodious" group of transformations. His paper, published in The Monist in 1898, was the deepest of his contributions to this question at the time. He did not seek to elude either the problems of compensation and approximation or the more general problem of the relationships between experiences and laws. Rather, he proposed that we impose certain features on Nature through certain active operations of the mind. In his view, though, such imposition continually required the use of conventions.

When experience teaches us that a certain phenomenon does not correspond at all to these laws, we strike it from the list of displacements. When it teaches us that a certain change obeys them only approximatively, we consider the change, by an artificial convention, as the resultant of two other component changes. The first component is regarded as a displacement rigorously satisfying the laws of which I have just spoken, while the second component, which is small, is regarded as a qualitative alteration. [Poincaré 1898, 11]

Poincaré stressed several times that one of the consequences of his theory is that there is no need for a primary notion of space; the notion of space follows from the consideration of properties of displacements (which are changes of sensations). In 1898, there was no problem for Poincaré: Geometry precedes Space.

From this point of view, Poincaré's conceptions were original compared to such predecessors as Riemann, Helmholtz, Lie or Klein, who presupposed the existence of an amorphous continuum in the development off their geometrical theories.

[...] we must distinguish in a group the form and the matter [material]. For Helmholtz and Lie the matter of the group existed previously to the form, and in geometry the matter is a Zahlenmannigfaltigkeit of three dimensions. ${ }^{12}[\ldots]$ It is only by the introduction of the group, that they made of it a measurable magnitude, that is to say a veritable space. Again, the origin af this non-measurable continuum of three dimensions remains imperfectly explained. [Poincaré 1898, 40]

This "3-dimensional non measurable continuum" is the space of analysis situs which will be considered later by Poincaré as qualitative geometry. In 1898, Poincaré claimed that he didn't need the prerequisite of a three dimensional continuum. Very often, the hypothesis of a general space on which the geometry is constructed comes with the idea of a general geometry or a qualitative geometry which more or less embraces all metrical geometries. We thus see why, at that time, Poincaré's philosophical thinking could not agree with the general geometry of Calinon which presupposed the existence of an amorphous space. Moreover, it is untenable to use Calinon's theory to defend a psycho-physiologic point of view of the genesis of geometry since, for Calinon, geometry has no experimental foundation. In the same manner, Poincaré rejected theories like Russell's ${ }^{13}$ which put projective geometry at the beginning of the genesis of metrical geometry. All these theories reduce the importance of experience to the choice of the metrical geometry in which we describe our common or physical experience, while all also admit a general a priori geometrical framework.

In his 1898 paper, Poincaré put forward a (mathematical) explanation of the three dimensions of space. He observed that the Euclidean group, selected after many conventions, can be seen

\footnotetext{
${ }^{12}$ Poincaré adds that for him, « on the contrary, the form exists before the matter ».

${ }^{13}$ See [Nabonnand 2000a].
} 
as acting on a space of three, four or five dimensions. ${ }^{14}$ The choice of a three dimensional space is justified by considerations of commodity. Unfortunately, Poincaré's argument is vicious because the choice of the Euclidean group was grounded on Lie's classification of groups of transformations acting on $\mathbb{R}^{3}$ and admitting a fundamental invariant. In 1903, Poincaré (after his work on analysis situs and his first debate with Russell about the status of the axioms of geometry) returned to the question of the dimension of space in a paper titled "L'espace et ses trois dimensions" [Poincaré 1903].

This paper deals with the question of the status of the space in analysis situs which Poincaré presents as the common background for the Euclidean and non-Euclidean spaces. After claiming once more that Euclidean geometry could not be a "form imposed on our sensibility", he asks if the amorphous continuum of the Analysis situs is a "form imposed to our sensibility":

And then comes a question: Is not this amorphous that our analysis has allowed to survive a form imposed upon our sensibility? If so, we should have to enlarge the prison in which this sensibility is confined, but it would still remain a prison. [VS, 40]

The same questions concerning the truths of Euclidean geometry come up anew about the theorems of analysis situs. Are they obtainable by deductive reasoning? Are they the disguised conventions? Are they experimental truths? Are they the characteristics of a form imposed either upon our sensibility or upon our understanding? [VS, 40-41] ${ }^{15}$

Poincare answers these questions with the analysis of the genesis of the geometry. The general properties of the amorphous continuum are obtained with the same process as the metrical properties. In 1898, Poincaré argued that the notion of displacement was obtained as a change of the sensible (or representative) space. It is as if the displacements set up a continuous group of transformations without the group acting on the representative space:

The complex of our sensations has without doubt furnished us with a sort of matter, but there is a striking contrast between the grossness of this matter and the subtle precision of the form of our group. [Poincaré 1898, 41]

In addition to the experiment of the composition of displacements, which makes us act as if the displacements form a group, we consider the possible repetition of displacements. When the displacement $\mathrm{D}$ is very small, we experience what Poincaré calls physical continuum. We can sum up this notion by the formula:

$$
9 \mathrm{D}=10 \mathrm{D}, 10 \mathrm{D}=11 \mathrm{D}, 9 \mathrm{D}<11 \mathrm{D}
$$

As Poincaré claimed, this formula is intolerable for our reason and empirical data impose on us the need to create the mathematical continua so as ensure the continuity of the group of displacements. Of course, this solution imposes itself because it is in agreement with other properties of the group. If these properties were incompatible with the hypothesis of continuity, we would be forced to choose another hypothesis. For Poincaré, the group of

\footnotetext{
${ }^{14}$ For more details, see [Nabonnand 2000b].

15 «Et alors une question se pose : ce continuum amorphe, que notre analyse a laissé subsister, n'est-il pas une forme imposée à notre sensibilité ? Nous aurions élargi la prison dans laquelle cette sensibilité est enfermée, mais ce serait toujours une prison ».

« Les mêmes questions qui se posaient à propos des vérités de la géométrie euclidienne, se posent de nouveau à propos des théorèmes de l'Analysis Situs. Peuvent-ils être obtenus par un raisonnement déductif ? Sont-ce des conventions déguisées ? Sont-ce des vérités expérimentales ? Sont-ils les caractères d'une forme imposée soit à notre sensibilité, soit à notre entendement ? »
} 
displacements resulting from the analysis of changes of sensations and the geometrical groups of transformations entertain the same kind of relationship as do physical and mathematical continua.

We first study its form agreeably to the formula of the physical continuum, and since there is something repugnant to our reason in this formula we reject it and substitute for it that of the continuous group which, potentially, pre-exists in us, but which we originally know only by its form. The gross matter which is furnished us by our sensations was but a crutch for our infirmity, and served only to force us to fix our attention upon the pure idea which we bore about in ourselves previously. [Poincaré $1898,41]$

The choice of the mathematical continuity results from convention inferences; the geometrical space is continuous because the group of geometrical transformations is. The aim of analysis situs is to study properties of mathematical space which are linked with the property of continuity; the choice of the 3-dimensionality of space reflects the inferential commodiousness of considering the internal action of the group of transformations on the set of its subgroups. ${ }^{16}$

In 1905, Poincaré advocated a significantly different explanation of the choice of the hypothesis of the continuity of space. Poincaré began by asking what " is meant when we say that a mathematical continuum or that a physical continuum has two or three dimensions" [VS, 42]. He introduced the notion of cut in the context of physical continuum. If any two (physically) discernible elements of a physical continuum $C$ can be linked by a path of indiscernible elements (a physically continuous path), the physical continuum $C$ is called "all in one piece (d'un seul tenant)". A cut is an arbitrary set of elements of $C$. According to the choosen cut, the physical continuum $C$ remains "d'un seul tenant" (i.e. any two discernable element can either be linked by a path of indiscernable elements without leaving $C$ and without crossing the cut) or it will be divided by the cut. Poincare pointed out that these definitions are all suggested by experience:

It will be noticed that all these definitions are constructed in setting out solely from this very simple fact, that two manifolds of impressions sometimes can be discriminated, sometimes can not be. [VS, 43]

We say that a physical continuum is 1-dimensional if we cut it by one or several discernable elements. A physical continuum is said 2-dimensional if we can cut it by one or several 1dimensional cut (and implied it cannot be cut by one or several discernable elements). And so on. ${ }^{17}$

This definition of the definition of physical continuum allowed Poincaré to break the vicious circle of his former theory of the 3-dimensionality of space. For a time, Poincaré abandoned part of his early theory. Certainly, the physical continuum formed by the displacements is 6dimensional and this result comes from experience. Poincaré claimed he could maintain his previous theory and keep infering the 3-dimensionality of the geometrical space from the internal action of the group of its subgroup. But it would be difficult because he would still have to justify the utilization of Lie's classification of groups of transformations acting on $\mathbb{R}^{3}$.

\footnotetext{
${ }^{16}$ For more details, see [Nabonnand 2000].

${ }^{17}$ Poincaré specified that this definition is the same as the one of geometers who defined surfaces as boundaries of volumes, and lines as boundaries of surfaces and points as boundaries of lines. He added that this form of definition is "applicable not to the mathematical continuum, but to the physical continuum, which alone is susceptible of representation" [VS, 44].
} 
Poincaré didn't mention this problem. He simply argued that such a theory could not be completely satisfying because it does not respect the hierarchy of our spatial sensations:

[...]; and when we shall have shown how the notion of this continuum [the group of displacements] can be formed and how that of space may be deduced from it, it might always be asked why space of three dimensions is much more familiar to us than this continuum of six dimensions, and consequently doubted wether it was this detour that the notion of space was formed in the human mind. [VS, 57-58 $]^{18}$

So Poincaré added to his theory a new stage explaining why we are guided (by experience) towards a 3-dimensional physical continuum. Here, the most essential space is that which is associated with the sense of touch. Poincare argued that a necessary condition for the setting up of the tactile space is that tactile sensations are not falsified by muscular ones which are associated with our movements. Each space which is associated with our fingers is a 3dimensional physical continuum. Poincaré argued that, on the basis of experiences, we are led to consider them all as similar. He argued as well that we are led to assimilate the visual space to these tactile spaces.

So if Poincaré in 1905, at the beginning af his genesis of the geometry, included 3 dimensional physical continuum, he didn't do so for epistemological reasons, for reasons linked to intuition, or for mathematical reasons. Rather, he did it for reasons of coherence. He felt forced to admit a rough notion of 3-dimensional space in order to justify his utilization of Lie's classification of 6-parameter groups of transformations acting on $\mathbb{R}^{3}$. Similarly for admission of a significant invariant. Finally, he also wanted to explain why the 3dimensionality of geometrical space is so immediate. He pointed out, however, that as in his previous views, experience plays an essential role at each stage of the genesis of geometry. This notwithstanding, he did not lapse into fruitless and beatific empiricism. Rather, he emphasized that "experience does not prove to us that space has three dimensions; it only proves to us that it is convenient to attribute three to it, because the number of fillips is thus reduced to a minimum" [VS, 69].

The choice of conventions is justified according to cases by considerations concerning accomodation of our experience, or by reasons of practical or mathematical usefulness. The choice of conventions can take different forms, including the definition of new objects. As Poincaré recalled, a convention is never imposed by experience. It is only the result of a capacity of our mind and experience provides us the occasion to use this capacity. According to Poincaré, we have innate capacities to set up groups and continua. To understand the genesis of geometry is to understand how experiences provide the innate capacities of our mind the occasion to manifest themselves. So conventions are neither themselves intuitions, nor the results of intuitions. Rather, they are the result of the activation by experience of innate capacities of our minds.

So we have the same situation as for the genesis of the recurrence principle in arithmetic: experience provides our mind the occasion to use his capacities; when we do not have a choice, the role of experience comes to an end and the result is a principle of reasoning. When we have choice, experience helps us to choose and the result is a convention. It is therefore clear that the second characteristic of Heyting cannot be applied to Poincaré. For Poincaré, mathematical theories and methods are dependent on outer experience in that it is experience which provides our minds occasion to apply its innate capacities.

\footnotetext{
${ }^{18}$ This kind of cognitive and genetic argument is typical of Poincaré. He refused to consider projective geometry as a type of general geometry because "this evidently is not the manner in which our geometrical notions were formed" [Poincaré 1898, 35].
} 
Conclusion. - We are accustomed to taking some mathematical conceptions of Poincaré and Brouwer as being rather closely related. This is perhaps especially so in the case of their criticisms of logicism and their common conviction concerning the central role of the idea of indefinite repetition. The latter serves to justify complete induction and to introduce the notions of the (mathematical) continuum or transformation groups. Both preferred the group theoretic presentation of geometry over its Hilbert's style axiomatic presentation, and both also declined to attach an a priori character to Euclidean geometry.

From a conceptual point of view, however, Poincaré and Brouwer are basically different in their approaches. Whereas Brouwer considered the possibility of indefinite repetition to be a sort of instantiation of the pure intuition of time [Brouwer 1912, 127/128], Poincaré regarded it as the result of the excitation by experience of the mind's power "to conceive of the indefinite repetition of the same act, when the act is once possible" [SH, 41]. Similarly, the notions of 'mathematical continuum' and 'group transformations' are attained thanks to the power of the mind to form continua or groups but Poincaré always took care to underline the fact that it is experience that provides the mind the occasion for such self-activation. Furthermore, he took the use of these concepts to account for experience as a type of convention.

Poincare and Brouwer were in agreement on the idea that one should attach the greatest fundamental character to analysis situs. Nevertheless, Brouwer, in adopting Klein's subordination principle, justified his appraisal by the fact that the group of continuous transformations is the most general group operating over a continuum. For Poincaré, on the other hand, the special character of analysis situs lies in the fact that what it studies as the common part of the three Euclidean and Non Euclidean geometries are those properties that are in the relation to the continuity of the transformation group to which we relate our spatial considerations. Finally, Brouwer stipulates the preliminary existence of the continuum as the operator domain of the continuous transformations. Poincaré's approach (in 1903) is much more genetic; he argues that we acquire our experience of a three dimensional physical continuum through our tactile sense. This experience allows us to justify the use of Lie's classification of transformation groups operating upon $\mathbb{R}^{3}$ to describe the process of choice in favor of the Euclidean group. The Euclidean space and its elements are constructed with regard to results obtained for the group structure.

By adopting his group theoretic conception of geometry, Poincaré expressed his dissatisfaction with a purely formal approach to the foundations of mathematics. $\mathrm{He}$ recognized clearly the mathematical equivalence of his own presentation to the axiomatic presentation. He nonetheless emphasized in his review of Hilbert's Grundlagen der Geometrie that Hilbert's preference for the axiomatic approach reflected his (i.e. Hilbert's) rather too exclusive focus on the logical point of view and paid little attention to questions concerning the justification of the axioms or their psychological origins [Poincaré 1902b, 45]. These considerations make it clear that Poincaré preferred his group theoretic approach for cognitive reasons despite the fact that the axiomatic presentation may satisfy all demands of rigor. ${ }^{19}$ And in fact, it turns out that the notion of geometrical transformation is much better adapted than the axiomatic presentation to the illustration of that part of experience which is involved in the shaping of mathematical concepts. What is most striking to us about Poincaré's philosophy, when compared to empiricism, intuitionism and formalism, is its view of the role of outer experience in the genesis of fundamental mathematical concepts. It is

\footnotetext{
${ }^{19}$ Poincaré specifies that all geometries (Non Archimediean, Non Pascalean...) discussed by Hilbert can be formulated as geometries associated to a group [Poincaré 1902b, 45].
} 
neither merely a prop for abstraction nor something which in the end reduces to the mere manipulation of signs. Poincaré seeks to clarify the importance of the linguistic level in mathematical thinking. Contrary to the intuitionists, the use of language is for him not only an efficient tool for memorizing or communicating but also and above all an essential part of the genesis of mathematical conceptualization. It is an integral part of the whole experimental frame on which our inner faculties are grounded $^{20}$.

\section{Bibliography}

Ben-Menahem, Yemina

[2001] Convention: Poincaré and some of his critics, British Journal for the Philosophy of Science 52 (3), 471-513.

Beth, Evert William

[1956] Poincaré et la philosophie, in : Poincaré, CEuvres, publiées sous les auspices de l'Académie des Sciences, Paris: Gauthier-Villars, vol. 11, 232-238.

Brouwer, Luitzen Egbertus Jan

[1907] Over de Grondlagen der Wiskunde, in: A. Heyting 1975, 11- 101.

[1908] Het wezen der meetkunde, cité d'après la trad. Anglaise, The nature of geometry, OC 1, 112-122.

[1912] Intuitionism and Formalism (Inaugural address, read 1912), quoted in: Heyting, 123-138.

[1913] Über den naturlichen Dimensionsbegriff, Journal für die reine und angewandte Mathematik, 142 (1913), 146-152.

[1924] Zum natürlichen Dimensionsbegriff, Mathematische Zeitschrift, 21 (1924), 312-314.

[1952] Historical Background, Principles and Methods of Intuitionism, South African Journal of Science, 49, 139-146. 551-554.

[1955] The Effect of Intuitionism on Classical Algebra of Logic, in: A. Heyting 1975,

Detlefsen, Michael

[1992] Poincaré against the Logicicians, Synthese 90, 349-378.

[1993] Logicism and the Nature of Mathematical Reasoning, in: A. Irvine/G.

Wedekind (eds.), Russell and Analytical Philosophy, Toronto: Univ. Press, 265-292.

Dubucs, Jacques

[1988] L. J. E. Brouwer : topologie et constructivisme, Revue d'histoire des sciences, 41 (1988), 133-155.

Edwards, Harold

[1988] Kronecker's Place in History, in: W. Aspray/P. Kitcher (ed.), History and Philosophy of Modern Mathematics, Minneapolis: Minnesota Press, 139-144.

Février, Paulette

\footnotetext{
${ }^{20}$ We are grateful for comments we received from Mark van Atten, Micheal Detlefsen and Prosper Doh.
} 
[1981] La philosophie mathématique de Poincaré, Epistemologia, 4 (n॰1), 151-172.

Folina, Janet

[1992] Poincaré and the Philosophy of Mathematics, Houndmills/London: MacMillan.

Goldfarb, Warren

[1988] Poincaré against the Logicists, in: W. Aspray/P. Kitcher (ed.), History and Philosophy of Modern Mathematics, Minneapolis: Minnesota Press, 61-81.

Greffe, Jean-Louis, Heinzmann, Gerhard and Lorenz, Kuno (eds)

Blanchard.

[1996] Henri Poincaré. Science and Philosophy, Berlin/Paris: Akademie Verlag /

Heinzmann, Gerhard (ed.)

[1986] Poincaré, Russell, Zermelo et Peano. Textes de la discussion (1906-1912) sur les fondements des mathématiques: des antinomies à la prédicativité, Paris: Blanchard.

Heyting, Arend Springer.

[1934] Mathematische Grundlagenforschung, Intuitionismus, Beweistheorie, Berlin:

Heyting, Arend (ed.)

[1975] Brouwer, Collected Works 1, Amsterdam/Oxford/New York: NorthHolland/Elsevier.

Hintikka, Jaakko

[1996] The Principle of Mathematics Revisited, Cambridge: University Press.

Kleene, Stephen Cole Holland.

[1980] Introduction to Metamathematics, (11952), Amsterdam/Groningen: North-

Largeault, Jean

[1993] Intuition et intuitionisme, Paris: Vrin.

McLarty, Colin 115.

[1997] Poincaré: Mathematics \& Logic \& Intuition, Philosophia Mathematica, 5, 97-

Mooij, J.J.A.

[1966] La Philosohie des Mathématiques de Henri Poincaré, Paris/Louvain: GauthierVillars/Nauwelaerts.

Nabonnand, Philippe

[2000a] La polémique entre Poincaré et Russell au sujet du Statut des axiomes de la Géométrie, Revue d'Histoire des Mathématiques, 6 (2000), 219-269.

[2000b] La genèse psycho-physiologique de la géométrie selon Poincaré, Textes du séminaire «Histoires de Géométries» 2000, Maison des Sciences de l’Homme, 2000.

Poincaré, Henri 
[1898] On the Foundations of Geometry, The Monist, 9 (1898), 1-43; French translation from the English version by L. Rougier, Des fondements de la géométrie, Paris: Chiron; quoted from [Poincaré 2002], 5-46.

[1902a] La Science et l'hypothèse, Paris: Flammarion, 1968; Engl. translation: Science and Hypothesis, London: The Walter Scott Publ.,1905 (abbreviated SH).

[1902b] Les fondements de la géométrie - Grundlagen der Geometrie par M. Hilbert, professeur à l'Université de Göttingen, Bulletin des sciences mathématiques, $26\left(2^{\mathrm{e}}\right.$ série), 249-272; O.C. 11, 92-113; cite d'après [Poincaré 2002], 33-46.

[1903] L'espace et ses trois dimensions, Revue de métaphysique et de morale, 11(1903), 281-301, 407-429 ; quoted from La valeur de la science, chapter III and IV.

[1905] La Valeur de la science, Paris: Flammarion, 1970; Engl. translation: The Value of Science, New York: Dover 1958 (abbreviated VS).

[1906] Les Mathématiques et la logique, Revue de métaphysique et de morale, 14, 294-317; reprinted in: Heinzmann 1986, 79-104.

[1908] Science et méthode, Paris: Kimé, 1999; Engl. translation: Science and Method, London/New York: Thomas Neldon \& Sons, no date (abbreviated SM).

[1913] Dernières pensées, Paris: Flammarion, 1963; Engl. translation: Mathematics and Science: Last Essays, New York: Dover 1963 (abbreviated DP).

[2002] L'opportunisme scientifique, compiled by L. Rougier, edited by L. Rollet, Basel.Boston.Berlin: Birkhäuser, 2002.

Resnik, Michael D.

[1996] On Understanding Mathematical Proofs, in: Greffe et al. 1996, 459-466. 